\title{
Avaliação de risco à saúde humana associada ao consumo de águas subterrâneas contaminadas em Capitão Gervásio de Oliveira, Estado do Piauí
}

\author{
Zuleica Castilhos ${ }^{1 *}$ \\ Ricardo Cesar ${ }^{2}$ \\ Ricardo Sierpe ${ }^{2}$ \\ Jenesca Florencio' \\ Patricia Araujo ${ }^{1}$ \\ ${ }^{1}$ Centro de Tecnologia Mineral, Ministério \\ da Ciência e Tecnologia (CETEM/MCT) - \\ Rio de Janeiro (RJ), Brasil. \\ ${ }^{2}$ Universidade Federal Fluminense (UFF) - \\ Niterói (RJ), Brasil. \\ *Autor correspondente: zcastilhos@cetem. \\ gov.br
}

\section{Resumo}

Os riscos potenciais à saúde humana associados à presença de elementos traços ( $\left.\mathrm{Ba}, \mathrm{B}, \mathrm{Ni}, \mathrm{Hg}, \mathrm{Zn}, \mathrm{Mg}, \mathrm{Ca}, \mathrm{K}, \mathrm{P}, \mathrm{Na}, \mathrm{Cl}^{-}, \mathrm{F}^{-}\right)$e patógenos fecais foram avaliados em 12 poços de captação de água subterrânea em Capitão Gervásio de Oliveira, Piauí. A metodologia de avaliação de risco à saúde humana proposta pela Agência Americana de Proteção Ambiental foi utilizada para a estimativa numérica dos riscos relacionados à exposição ambiental por $\mathrm{Ni}$, $\mathrm{Hg}, \mathrm{Zn}, \mathrm{B}$ e Ba. A determinação dos coliformes totais e de Escherichia coli foi realizada com o emprego do método Colilert. Todas as concentrações obtidas foram comparadas aos padrões de qualidade recomendados pela legislação brasileira. Os resultados mostraram que os teores da maior parte dos elementos estudados estão abaixo dos valores máximos estipulados pela legislação, com exceção do $\mathrm{Hg}, \mathrm{Ni}$ e $\mathrm{Cl}^{-}$. Todos os poços estudados mostram águas inapropriadas para o consumo humano quando se considera a contaminação por coliformes. Ainda, a estimativa numérica do risco total à saúde humana indicou que o $\mathrm{Ni}$ e o $\mathrm{Hg}$ são os metais que mais efetivamente participam do acréscimo de perigo, devendo ser priorizados em ações que decresçam os teores desses metais-traço nas águas consumidas pela população. Palavras-chave: águas subterrâneas, semiárido, saúde humana, risco.

\section{Abstract}

Potential risks on human health associated with trace elements ( $B a, B$, $\mathrm{Ni}, \mathrm{Hg}, \mathrm{Zn}, \mathrm{Ni}, \mathrm{Mg}, \mathrm{Ca}, \mathrm{K}, \mathrm{P}, \mathrm{Na}, \mathrm{Cl}, \mathrm{F}$ ) and fecal pathogens exposure were evaluated in 12 groundwater samples from supply wells at the Capitão Gervásio de Oliveira Municipality, Piauí, Brazil. The methodology for human health risk assessment, established by the American Agency for Environmental Protection, was applied in order to numerically estimate the risks associated with $\mathrm{Ni}, \mathrm{Hg}, \mathrm{Zn}, \mathrm{B}$ and Ba exposure. Total coliforms and Escherichia coli were quantified using the Colilert method. The concentrations were compared to the values defined by the Brazilian environmental law. The results revealed that most concentrations were in disagreement with the values defined by the Brazilian legislation, especially $\mathrm{Hg}, \mathrm{Ni}$ and $\mathrm{Cl}$. In terms of coliforms pollution, all samples were inappropriate for human consumption. The numerical estimation of the total risks on human health indicated that $\mathrm{Ni}$ and $\mathrm{Hg}$ are the metals that most effectively increase the hazard, suggesting that actions should be focused on decreasing such levels in drinking water.

Keywords: groundwater, Brazilian semi-arid zone, human health, risk. 


\section{INTRODUÇÃO}

A região nordeste do Brasil é tradicionalmente castigada pela escassez de água, além de apresentar baixos níveis de desenvolvimento socioeconômico. A gestão sustentável e integrada dos recursos hídricos subterrâneos em determinadas áreas-chave poderia modificar esse quadro. No entanto, a carência de estudos em escala regional com a localização, caracterização físico-química das fontes hídricas e sua disponibilidade - inviabiliza a gestão mais eficiente e integrada dos recursos hídricos subterrâneos, comprometendo a elaboração de planos emergenciais em períodos de seca. Esse quadro ocorre também no Estado do Piauí.

O Centro de Tecnologia de Mineral (CETEM) - um instituto de pesquisas do Ministério da Ciência, Tecnologia e Inovação (MCTI) - em seu Campus Avançado no Piauí, tem proposto o desenvolvimento de abordagens visando o gerenciamento sustentável dos recursos minerais do Estado do Piauí, incluindo as águas subterrâneas. Nesse sentido, a proposta do CETEM consiste no emprego da metodologia de avaliação de risco à saúde humana como ferramenta para gestão sustentável dos recursos hídricos subterrâneos do Estado. Para tanto, inicialmente foram definidas e reunidas informações necessárias para alimentar um banco de dados em Sistema de Informação Geográfica (SGI), visando o gerenciamento e mapeamento das atividades potencialmente poluidoras no Estado do Piauí. Foram utilizadas as informações socioeconômicas municipais, dados do Instituto Brasileiro de Geografia e Estatística (IBGE) acerca das atividades agropecuárias, industriais e de serviços, e dados disponibilizados pelo Departamento Nacional de produção Mineral (DNPM) sobre os processos minerários (incluindo o tipo de minério, a localização geográfica de pesquisas minerais, concessão de lavra, entre outros). A partir das análises sobre o tipo de atividade antrópica predominante no Estado, foram selecionados, em ordem de prioridade,

\section{MATERIAIS E MÉTODOS}

\section{1. Área de estudo}

O município de Capitão Gervásio de Oliveira está localizado na porção leste do Piauí (08 $29^{\circ} 25^{\prime}$ " de latitude sul; 41 $49^{\circ} 11^{\prime \prime}$ de longitude oeste), a aproximadamente $550 \mathrm{~km}$ da capital estadual Teresina, e compreende uma área de $1.510 \mathrm{~km}^{2}$ (CPRM 2004). A população total, segundo o Censo 2010 do IBGE (2010), é de 3.876 habitantes, com uma densidade demográfica de $2,6 \mathrm{hab} / \mathrm{km}^{2}$. O clima do município é semiárido (quente e seco), com temperaturas anuais variando entre 16 (mínima) e $36^{\circ} \mathrm{C}$ (máxima) (CPRM 2004).

A geologia regional é marcada por dois domínios bem definidos: rochas cristalinas pré-cambrianas e rochas sedimentares da Bacia do Parnaíba (Figura 1). No que se refere ao embasamento cristalino, a hidrogeologia do município é caracterizada pela ocorrência de aquíferos fissurais, que representam $50 \%$ da área total do município (CPRM 2004). os contaminantes de interesse e áreas/municípios (divisão política) a serem estudados.

Com base no referido banco de dados, Capitão Gervásio de Oliveira, Piauí, foi escolhido para a realização de um estudo piloto envolvendo a avaliação de risco à saúde humana associada ao consumo de água subterrânea de poços de abastecimento. As razões que justificaram a escolha desse município se devem à indicação de uma mina de níquel (metal de reconhecida toxicidade), ao abastecimento público de águas (predominantemente subterrâneas, sob responsabilidade da Prefeitura Municipal) e à receptividade do Poder Público Municipal à proposta do presente estudo.

O monitoramento da contaminação por elementos traços e patógenos em águas subterrâneas é tradicionalmente realizado pelo viés da hidrogeoquímica, que busca compreender e modelar o comportamento desses contaminantes em aquíferos. Associar essa abordagem à toxicologia permite fornecer uma estimativa numérica do risco potencial à saúde humana, incluindo os efeitos aditivos de distintos contaminantes sobre o organismo humano (Castilhos et al. 2005). Nesse sentido, a aplicação da metodologia de avaliação de risco à saúde humana, proposta pela Agência Nacional de Proteção Ambiental Americana (USEPA 1989), pode complementar os dados oriundos da geoquímica analítica. A metodologia supracitada trata da geração de índices numéricos capazes de indicar a ocorrência de áreas críticas a serem priorizadas em programas de saúde pública e de controle ambiental (USEPA 1989, Castilhos et al. 2005), permitindo uma gestão mais eficiente de recursos limitados, tanto financeiros quanto humanos.

O presente trabalho trata da avaliação da qualidade de águas subterrâneas e dos riscos potenciais à saúde humana no município de Capitão Gervásio de Oliveira, Piauí.
Nesse sentido, no que se refere ao embasamento cristalino, a hidrogeologia do município é caracterizada pela ocorrência de aquíferos fissurais (de até $\sim 70 \mathrm{~m}$ de profundidade) que representam $50 \%$ da área total do município, com poços de baixas vazões $(\sim 5.000 \mathrm{~L} / \mathrm{h})$ e de elevada salinidade $(\sim 2,0$ partes por mil em média, com máximas de até 6,0$)$ em função do clima semiárido e do tipo de rocha (CPRM 2004). No que diz respeito às unidades sedimentares pertencentes ao Grupo Parnaíba, a hidrogeologia do município é representada pelo(a): (i) Grupo Serra Grande (de maior potencial hidrogeológico no município); (ii) Formação Pimenteiras (com menor potencial hidrogeológico); e (iii) Coberturas Colúvio-Eluviais (de comportamento granular, alta permeabilidade e de elevado potencial de armazenamento hídrico) (CPRM 2004) (Figura 1). 


\subsection{Amostragem}

O cadastro de poços existentes em cada município do Estado do Piauí foi obtido com base no Sistema de Informações de Águas Subterrâneas (SIAGAS/CPRM) e registros municipais. Dessa forma, foram coletadas, prioritariamente, águas subterrâneas de fontes públicas para abastecimento doméstico, que atendessem o maior número de moradores. A atualização das informações foi essencial, pois há uma grande dinâmica na abertura e fechamento de poços para abastecimento doméstico. Portanto, após a pré-seleção de poços públicos para abastecimento doméstico, a seleção final dos poços ocorreu em comum acordo com as instituições locais parceiras, ou seja, as Prefeituras Municipais, as
Secretarias Municipais de Meio Ambiente e de Saúde, e a Águas e Esgotos do Piauí S.A. (AGESPISA).

A distribuição espacial dos pontos de amostragem está apresentada na Figura 1. A amostragem de água subterrânea foi efetuada em 12 poços bem distribuídos pelo município, em agosto de 2010. Para a determinação dos elementos traços (vide item 2.3), as amostras foram armazenadas em garrafas de polietileno, acidificadas com $1 \mathrm{~mL}$ de ácido nítrico e $\mathrm{HNO}_{3}$ e mantidas a $5^{\circ} \mathrm{C}$. Para a avaliação dos coliformes totais e fecais, as águas foram coletadas sem adição de ácido e analisadas no mesmo dia de coleta.

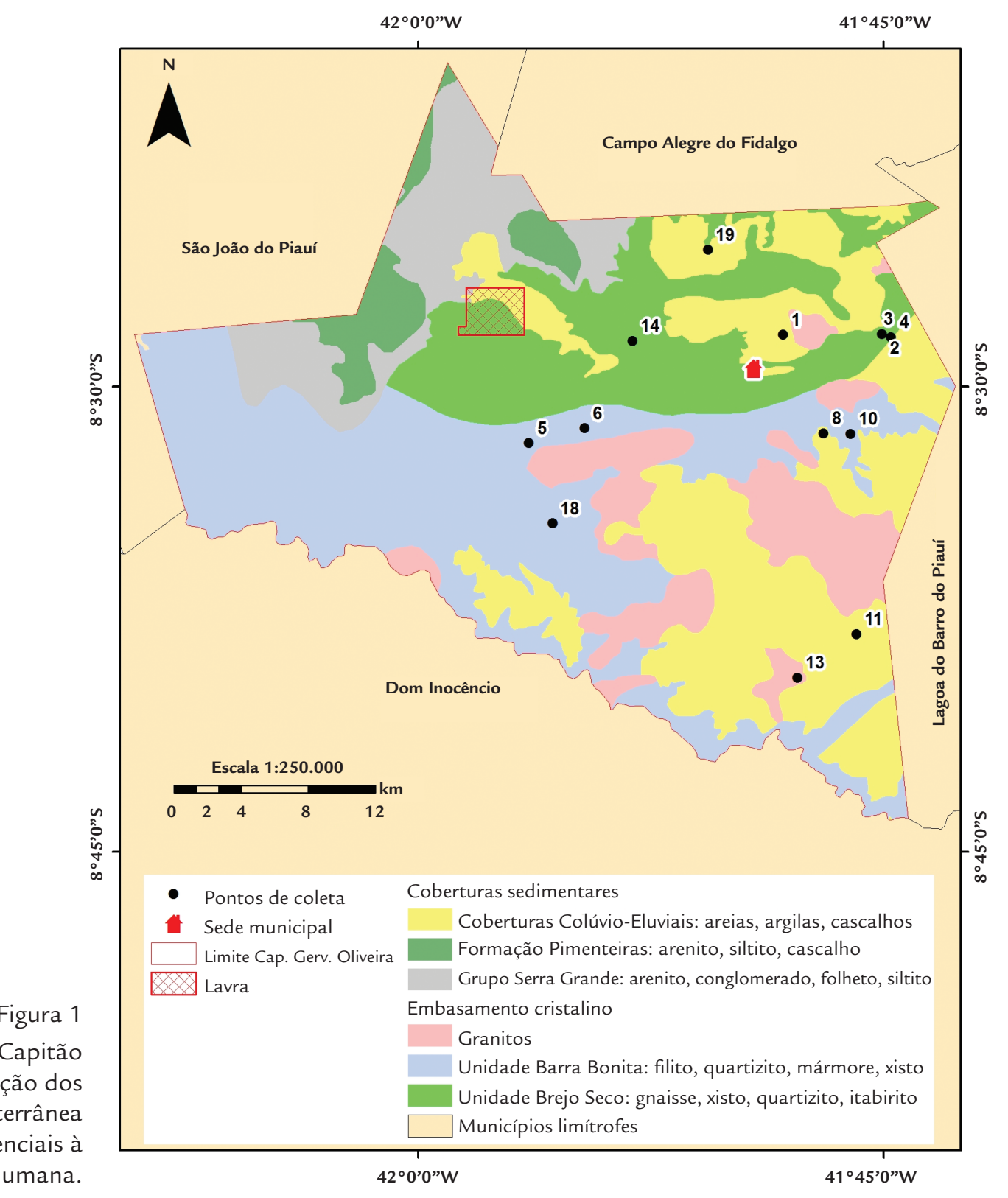




\subsection{Caracterização hidroquímica e determinação de elementos traços}

Após revisão bibliográfica detalhada a respeito do uso do solo e da geoquímica regional, os seguintes elementos químicos foram selecionados para quantificação: $\mathrm{Ba}, \mathrm{B}, \mathrm{Ni}$, $\mathrm{Hg}, \mathrm{Zn}, \mathrm{Mg}, \mathrm{Ca}, \mathrm{K}, \mathrm{P}$ e Na. A determinação do teor total dos referidos elementos foi efetuada em amostra bruta. $\mathrm{O}$ procedimento analítico envolveu a concentração de $100 \mathrm{~mL}$ de amostra para $25 \mathrm{~mL}$, com posterior adição de $5 \mathrm{~mL}$ de água régia $\left(3 \mathrm{HCl}: 1 \mathrm{HNO}_{3}\right)$ em béquer de vidro. Após a adição dessa mistura ácida, a amostra foi mantida em chapa aquecedora a $150^{\circ} \mathrm{C}$. Para evitar a perda de metais altamente voláteis (como o $\mathrm{Hg}$ ), uma solução complexante foi previamente adicionada à solução analítica. Após essa etapa, a solução obtida foi avolumada para $50 \mathrm{~mL}$, sendo a determinação efetuada em ICP-OES (marca VARIAN, modelo VISTA-MPX, Austrália). Os métodos descritos são rotineiramente utilizados pelo CETEM na caracterização química de amostras líquidas e sólidas.

A determinação da concentração de cloreto $\left(\mathrm{Cl}^{-}\right)$consistiu na pipetagem de $25 \mathrm{~mL}$ de amostra para um béquer de vidro, ao qual foi adicionado $1 \mathrm{~mL}$ de $\mathrm{H}_{2} \mathrm{SO}_{4} 1 \mathrm{M}$. A mistura obtida foi avolumada para $50 \mathrm{~mL}$, para leitura com eletrodos de íon seletivo (marca Meter - HANNA, modelo HI 98185, Romênia). A quantificação de fluoreto ( $\mathrm{F}^{-}$) envolveu a adição de $25 \mathrm{~mL}$ uma solução tampão Total Ionic Strenght Adjusment Buffer (TISAB), sendo a leitura efetuada com eletrodos de íon seletivo.

A avaliação da intensidade da contaminação por elementos traços foi realizada através da comparação com os valores orientadores da Portaria 2.914/11 do Ministério da Saúde e da CETESB (2005). O primeiro documento trata das concentrações limites de metais e outros íons maiores ( $\mathrm{Cl}^{-}$e $\left.\mathrm{F}^{-}\right)$em águas subterrâneas, enquanto que o segundo estabelece valores orientadores para metais para águas subterrâneas do Estado de São Paulo. A geração desses valores está baseada na ocorrência potencial de efeitos adversos à saúde humana. Além disso, foram considerados também os valores orientadores da Resolução 396 do Conselho Nacional de Meio ambiente (CONAMA 2008).

\subsection{Determinação de coliformes totais e Escherichia coli}

Para a investigação da presença de coliformes totais e de Escherichia coli foi utilizado o método Colilert (IDEXX 2002). Esse método é composto de dois nutrientes indicadores. O primeiro, o o-nitrofenil- $\beta$-D-galactopiranosídeo (ONPG), é capaz de ser degradado pela enzima de composição dos coliformes totais, a $\beta$-D-galactosidase, produzindo então onitrofenol, cujo produto é de coloração amarela. O segundo nutriente indicador é o $\beta$-D glucuronídeo (MUG), que possui a capacidade de ser degradado pela enzima $\beta$-glucuronidase da E. coli, resultando na formação do produto fluorescente 4-metil-umbeliferona. Já que a maioria dos não coliformes não conta com essas enzimas, eles não podem se reproduzir e interferir nos resultados.

A análise quantitativa através do método Colilert é dada pela cartela Quanti-tray que, após a selagem, incubação e contagem dos cubos (amarelos para coliformes totais

\subsection{Avaliação de risco potencial à saúde humana}

A avaliação de risco potencial à saúde humana, em abordagem de rastreamento, foi realizada com base nos procedimentos descritos em USEPA (1989). Nessa abordagem são assumidos valores conservadores de exposição e de riscos à saúde humana, visando indicar prioritariamente os contaminantes não perigosos em cenário de pior caso, e selecionar aqueles que merecem detalhamento (por exemplo, maior frequência de amostragem). A estimativa numérica dos riscos não cancerígenos à saúde humana foi efetuada através do cálculo do coeficiente de perigo (QP). Para tanto, a ingestão de água contaminada foi considerada a via potencial de exposição humana. Dessa forma, a dose administrada (DA) foi calculada conforme a Equação 1. O QP foi numericamente estimado através da razão entre a e azuis fluorescentes para E. coli, com o auxilio de uma luz ultravioleta, de $365 \mathrm{~nm}$ ), permite calcular o número mais provável (NMP) de microrganismos específicos em uma amostra de água, utilizando tabela de probabilidade com limite de confiança de 95\% (IDEXX 2002).

O método Colilert utiliza a tecnologia de substrato definido Defined Substrate Technology (DST), a qual é aprovada pelas organizações norte-americanas American Public Health Association (APHA), American Water Works Association (AWWA) e Water Environment Federation (WEF) e aceito como método rápido padrão de avaliação da qualidade da água no Standard Methods for the Examination of Water and Wastewater. Os resultados obtidos foram comparados com os padrões de potabilidade descritos pela Portaria 2.914/11 do Ministério da Saúde.

DA e as respectivas doses de referência obtidas junto ao Integrated Risk Information System (IRIS) (USEPA 2014): $\mathrm{Hg}=0,0003 \mathrm{mg} / \mathrm{kg} / \mathrm{dia} ; \mathrm{Ni}=0,0200 \mathrm{mg} / \mathrm{kg} / \mathrm{dia}$; $\mathrm{Ba}$ e $\mathrm{B}=0,200 \mathrm{mg} / \mathrm{kg} / \mathrm{dia} ; \mathrm{Zn}=0,300 \mathrm{mg} / \mathrm{kg} / \mathrm{dia}$. Quando o valor da razão excede a unidade, é caracterizado perigo à saúde humana, com a possibilidade de ocorrência de efeitos não cancerígenos por exposição ambiental a metais (para avaliação dos riscos cancerígenos não existe dose de referência toxicológica recomendada pela IRIS; a presença do contaminante, independente da concentração, já caracteriza a ocorrência potencial de risco).

O Î́ndice de Perigo (IP), que integra a exposição ambiental simultânea a diversos contaminantes, foi obtido através do somatório dos valores de QP. Quando o IP excede a unidade, é caracterizado perigo à saúde humana, 
decorrente dos efeitos aditivos de exposição aos diversos agentes tóxicos considerados.

$$
\mathrm{DA}=\mathrm{C} * \mathrm{Co} / \mathrm{P}
$$

Onde:

C: concentração do elemento em água; Co: consumo diário de água (2 L); P: peso corporal (20 kg para crianças e $70 \mathrm{~kg}$ para adultos).

\section{RESULTADOS E DISCUSSÃO}

\subsection{Caracterização hidroquímica}

Os resultados estão mostrados na Tabela 1. Os valores de pH estiveram em concordância com a Portaria 2.914/11 do Ministério da Saúde. Metade dos poços estudados apresentaram teores de sólidos totais dissolvidos (STD) acima do recomendado para a proteção da saúde humana. A determinação de $\mathrm{Ca}, \mathrm{P}, \mathrm{Mg}$, $\mathrm{K}$ e $\mathrm{Na}$ demonstrou a existência de relações positivas e significativas entre esses elementos, com base no coeficiente de correlação de Pearson $\left(r^{2}>0,5 ; p<0,001\right)$, conforme o esperado para águas salinas. Essa observação é ratificada pela constatação de correlações significativas entre a condutividade elétrica, salinidade, concentrações de $\mathrm{Cl}^{-}$e os referidos metais (Pearson, $\mathrm{r}^{2}>0,5 ; \mathrm{p}<0,001$ ), indicando que a maior parte desses íons estão disponíveis em solução e em associação com os cloretos, sobretudo no caso do K e Na, cujos coeficientes de correlação de Pearson estiveram acima de $0,85(\mathrm{p}<0,001)$.

A quantificação dos teores de $\mathrm{Na}$ revelou que 2 das 12 amostras analisadas estavam acima dos valores orientadores considerados (200 mg/L), isto é, impróprias para consumo humano. A quantificação de $\mathrm{F}^{-}$apresentou, em sua maior parte, teores baixos, sendo que na maioria dos pontos permaneceu abaixo do limite de detecção do método analítico. A determinação das concentrações de $\mathrm{Cl}^{-}$mostrou que $50 \%$ das amostras estavam acima dos valores orientadores considerados $(250 \mathrm{mg} / \mathrm{L})$, o que novamente sugere a ocorrência de águas salobras no Município de Capitão Gervásio de Oliveira, cujo consumo pode ser prejudicial à saúde humana. Outro aspecto importante é a variação espacial dos teores dos elementos, o que pode ser visto pela diferença entre mínimos e máximos dos elementos analisados, de até duas ordens de grandeza. Essa heterogeneidade é esperada, uma vez que a qualidade das águas subterrâneas oriundas de aquíferos fraturados mostra relação com o microambiente das rochas onde o aquífero está em contato e que podem mostrar grande variação de uma fratura para outra. Finalmente, os teores de elementos e metais também mostram ampla variabilidade espacial em função do método construtivo e do grau de proteção dos poços de águas subterrâneas para o abastecimento doméstico.

\subsection{Determinação de elementos traços}

As concentrações totais de metais em águas subterrâneas apresentaram não conformidade em relação aos teores orientadores considerados (à exceção da amostra 19), sugerindo a ocorrência potencial de efeitos adversos à saúde humana associados ao consumo de água contaminada. De forma geral, os elementos com maior frequência de concentrações acima do recomendado foram: $\mathrm{Zn}>\mathrm{Hg}>\mathrm{Ni}>\mathrm{Fe}>\mathrm{Ba}=\mathrm{Al}$. Os elementos $\mathrm{Ni}$ e $\mathrm{Hg}$ apresentaram concentrações acima dos valores orientadores em mais $60 \%$ dos pontos amostrados (Tabela 2), sendo que em $50 \%$ das amostras (poços 1, 2, 4, 8, 11 e 14) ambos mostraram teores acima dos recomendados. As mais elevadas concentrações desses metais estavam de três a cinco vezes maiores do que os valores recomendados para $\mathrm{Hg}$ e $\mathrm{Ni}$, respectivamente. A análise estatística revelou a existência de uma correlação positiva e significativa (Pearson, $r^{2}>0,5$; $\mathrm{p}<0,001)$ entre ambos os metais, sugerindo possível(is) fonte(s) comum(s) para esses elementos.

É provável que as concentrações anômalas de Ni possam estar associadas à presença do metal nas rochas da área estudada, tendo em vista a existência de jazidas/minas do metal na região, gerando anomalias hidrogeoquímicas e contaminação das águas subterrâneas. Por outro lado, deve-se ressaltar que o poço 19 , o mais próximo da mineração,

não mostra teores elevados de metais, incluindo Ni. Ainda, uma correlação positiva e significativa foi detectada entre o Ni e o Al (indicador de argilominerais; Pearson, $\mathrm{r}^{2}>0,5$; $\mathrm{p}<0,001$ ), sugerindo que o Al pode estar desempenhando papel importante na mobilidade do $\mathrm{Ni}$, possivelmente via transporte de material em suspensão. No que se refere ao $\mathrm{Hg}$, a via de ingestão de águas se refere à sua forma química divalente para a qual a absorção via gastrointestinal é baixa (menos de 10\%), mas deve-se ressaltar a importante toxicidade, podendo causar danos ao sistema renal, além de alterações bioquímicas e hematológicas, dependendo da dose (ATSDR 2007a).

Os teores de Al revelaram que somente 3 das 12 amostras analisadas estavam em discordância com os valores orientadores considerados (Tabela 2). O Al, em concentrações frequentemente presentes em águas de consumo humano $(<100 \mathrm{mg} / \mathrm{L})$, mostra baixa toxicidade associada à saúde (Barreto \& Araujo 2011).

A quantificação dos teores de $\mathrm{Pb}$ (elemento de importante toxicidade via ingestão) e de $\mathrm{B}$ revelou valores abaixo do limite de detecção dos métodos analíticos. Os teores de Zn estão em conformidade com os valores orientadores para todas as amostras analisadas (Tabela 2). O Zn é um micronutriente essencial com papel importante no metabolismo e fisiologia 


\begin{tabular}{|c|c|c|c|c|c|c|c|c|c|c|c|c|}
\hline Amostras & F.A. & $\mathrm{pH}$ & $\begin{array}{c}\text { Cond. } \\
\left(\mu \mathrm{S} . \mathrm{cm}^{-1}\right)\end{array}$ & $\begin{array}{c}\text { TSD } \\
(\mathrm{mg} / \mathrm{L})\end{array}$ & $\begin{array}{c}\text { Sal. } \\
\text { (partes } \\
\text { por mil) }\end{array}$ & $\mathrm{Ca}$ & $\mathbf{P}$ & $\mathrm{Mg}$ & K & $\mathrm{Na}$ & $\mathrm{Cl}^{-}$ & $F^{-}$ \\
\hline 1 & 90 & 6,5 & 936 & 459 & 0,4 & 74,96 & 0,008 & 32,85 & 5,41 & 18,15 & 47 & $<0,03$ \\
\hline 3 & 1 & DI & $\mathrm{DI}$ & $\mathrm{DI}$ & DI & 84,78 & 0,005 & 31,86 & 7,71 & 90,38 & 190 & $<0,03$ \\
\hline 4 & $\mathrm{DI}$ & DI & 1.096 & 539 & 0,5 & 102,94 & 0,016 & 32,12 & 7,07 & 89,81 & 153 & $<0,03$ \\
\hline 5 & 15 & 6,9 & 1.244 & 615 & 0,6 & 74,74 & $<0,005$ & 31,08 & 5,63 & 131,88 & 198 & $<0,03$ \\
\hline 10 & 5 & DI & 6.440 & $3.410^{*}$ & 3,5 & 448,03 & 0,023 & 249,39 & 65,62 & $481,12^{*}$ & $2067^{*}$ & $<0,03$ \\
\hline 11 & 6 & $\mathrm{DI}$ & 6.640 & $3.500^{*}$ & 3,6 & 465,72 & 0,125 & 294,97 & 34,38 & 630,14 & $585^{*}$ & $<0,03$ \\
\hline 13 & 10 & $\mathrm{DI}$ & 2.320 & $1.178^{*}$ & 1,2 & 151,32 & $<0,005$ & 75,15 & 41,57 & 114,97 & $703^{*}$ & $<0,03$ \\
\hline 14 & $\mathrm{NI}$ & $\mathrm{DI}$ & 8.910 & $4.850^{*}$ & - & 589,02 & 0,006 & 241,84 & 162,84 & $957,99 *$ & $4729 *$ & 0,5 \\
\hline 18 & Particular & $\mathrm{DI}$ & $\mathrm{DI}$ & $\mathrm{DI}$ & $\mathrm{DI}$ & 31,62 & 0,110 & 128,22 & 1,71 & 42,87 & 89 & $<0,03$ \\
\hline 19 & Comunidades & $\mathrm{DI}$ & $\mathrm{DI}$ & $\mathrm{DI}$ & $\mathrm{DI}$ & 83,1 & 0,041 & 44,57 & 7,57 & 36,06 & 114 & $<0,03$ \\
\hline Mínimo & - & 6,5 & 936,0 & 459 & 0,4 & 31,62 & 0,005 & 31,08 & 1,71 & 18,15 & 47 & $<0,03$ \\
\hline Máximo & - & 6,9 & $8.910,0$ & 4.850 & 3,6 & 589,02 & 0,110 & 294,79 & 162,84 & 957,99 & 4729 & 0,5 \\
\hline V. 0. & - & $6,5-9,5$ & $\mathrm{DI}$ & 1.000 & DI & $\mathrm{DI}$ & DI & DI & $\mathrm{DI}$ & 200 & 250 & 1,5 \\
\hline
\end{tabular}

*Acima do limite proposto pela portaria 518 do Ministério da Saúde.

F.A.: número de famílias atendidas; Cond.: condutividade elétrica; TSD: sólidos totais dissolvidos; Sal.: salinidade; DI: dado indisponível; V.O.: valor orientador da Portaria 2.914/11 do Ministério da Saúde e Resolução 396 (CONAMA 2008).
Tabela 1

Valores de $\mathrm{pH}$, condutividade elétrica, sólidos totais dissolvidos, salinidade e hidroquímica total $(\mathrm{mg} / \mathrm{L})$ das águas subterrâneas coletadas em Capitão Gervásio de Oliveira, Piauí.

\begin{tabular}{|c|c|c|c|c|c|c|c|c|}
\hline Amostras & $\mathrm{Al}$ & $\mathrm{Ba}$ & B & $\mathrm{Pb}$ & $\mathrm{Fe}$ & $\mathrm{Hg}$ & $\mathrm{Ni}$ & $\mathrm{Zn}$ \\
\hline 1 & 0,08 & $<0,02$ & 0,10 & $<0,004$ & 0,07 & $0,0029 *$ & $0,097^{*}$ & 0,009 \\
\hline 3 & 0,12 & 0,20 & 0,18 & $<0,004$ & 0,13 & $0,0027^{*}$ & 0,017 & 0,013 \\
\hline 5 & 0,05 & 0,10 & 0,14 & $<0,004$ & 0,06 & 0,0008 & $0,058^{*}$ & 0,009 \\
\hline 8 & $0,20 *$ & $5,80^{*}$ & 0,15 & $<0,004$ & $9,18^{*}$ & $0,0036^{*}$ & $0,749 *$ & 0,878 \\
\hline 10 & 0,10 & 0,27 & 0,33 & $<0,004$ & $8,8^{*}$ & $0,0018^{*}$ & 0,006 & 0,054 \\
\hline 14 & 0,13 & $0,84^{*}$ & 0,24 & $<0,004$ & 0,11 & $0,0031^{*}$ & $0,884^{*}$ & 0,023 \\
\hline 18 & 0,09 & $<0,02$ & 0,23 & $<0,004$ & $0,38^{*}$ & 0,0007 & 0,013 & 0,338 \\
\hline 19 & 0,05 & 0,07 & 0,15 & $<0,004$ & 0,19 & 0,0007 & 0,006 & 0,028 \\
\hline \multirow[b]{2}{*}{ Média } & 0,16 & $0,89 *$ & 0,18 & \multirow[b]{2}{*}{ DI } & $1,71^{*}$ & $0,0020^{*}$ & $0,28^{*}$ & 0,264 \\
\hline & \pm & \pm & \pm & & \pm & \pm & \pm & \pm \\
\hline CETESB (2005) & 0,20 & 0,70 & 0,50 & 0,01 & 0,30 & 0,0010 & 0,20 & 5 \\
\hline $\begin{array}{c}\text { Res. } 396 \\
\text { (CONAMA 2008) }\end{array}$ & 0,20 & 0,70 & 0,50 & 0,01 & 0,30 & 0,01 & 0,20 & 5 \\
\hline
\end{tabular}

*Acima do limite proposto pela CETESB (2005) e/ou portaria 518 do Ministério da Saúde e/ou Resolução 396 (CONAMA 2008).

DI: dado indisponível.
Tabela 2

Teores totais de elementos-traço ( $\mathrm{mg} / \mathrm{L})$ em amostras de águas subterrâneas coletadas em Capitão Gervásio de Oliveira, Piauí. 
de diversos organismos, pois atua como cofator enzimático e, dessa forma, é fundamental ao crescimento humano em condições de normalidade (ATSDR 2007b). Por outro lado, é importante assinalar que o Zn é também um bom indicador de contaminação por esgoto doméstico (Cesar et al.2011).

Os teores de Ba revelaram que 3 dos 12 pontos amostrados estavam acima do valor orientador considerado $(0,7 \mathrm{mg} / \mathrm{L})$ (Tabela 2). A mais elevada concentração de Ba esteve mais de oito vezes acima do valor orientador. Uma relação positiva e significativa foi detectada entre os teores de $\mathrm{Ba}$ e de Fe $\left(r^{2}>0,5 ; p<0,001\right)$ (indicador de oxi-hidróxidos de ferro), indicando que esse último pode estar desempenhando papel importante no comportamento do $\mathrm{Ba}$, principalmente através do transporte de material em suspensão. $\mathrm{O}$ Ba comumente ocorre em água sob a forma de carbonatos e sulfatos. Sua to- xicidade depende do ionte ao qual se encontra associado e da sua solubilidade em água e no estômago. Sob a forma acetato, hidróxido e nitrato, o Ba é altamente solúvel em água. Os sulfatos de Ba não são solúveis em água, mas podem ser solubilizados no estômago (ATSDR 2007c).

A determinação das concentrações de Fe revelou que das 12 amostras analisadas, 4 estavam em não conformidade com os valores orientadores (Tabela 2). A mais elevada concentração de Fe obtida estava mais de 30 vezes maior do que o valor orientador $(0,3 \mathrm{mg} / \mathrm{L})$ (Tabela 2$)$. De modo semelhante ao $\mathrm{Al}$, o Fe apresenta uma baixa toxicidade, e baixa e regulada absorção via gastrointestinal. Porém, obviamente, em doses tóxicas pode causar efeitos adversos aos sistemas digestivo, neurológico e cardiovascular, além de diabetes e câncer (Berber et al. 2007).

\subsection{Determinação de coliformes totais e de Escherichia coli}

As águas de consumo humano devem ser potáveis e, segundo a Portaria 2914/11 do Ministério da Saúde (BRASIL 2011), não são toleradas as ocorrências de coliformes totais e de Escherichia coli. Nesse sentido, todos os poços estudados mostraram-se em desconformidade com o referido limite orientador (Tabela 3). Somente os poços 5,8 e 11 apontaram para ausência de E. coli. O poço 4 apresentou a maior ocorrência de coliformes totais e E. coli (Tabela 3). Possivelmente a contaminação observada decorre da falta de saneamento básico, i.e., contato com esgoto doméstico e/ou com fezes de animais, em especial bodes, os quais são criados perto das casas, muitas vezes cercados em área adjacente aos poços. Nesse

\subsection{Avaliação de risco potencial à saúde humana}

A estimativa numérica de riscos não cancerígenos, em abordagem de rastreamento, para exposição ambiental de adultos via ingestão de águas, revelou a ocorrência de coeficientes de perigo acima de uma unidade apenas para o Ni, em 3 (amostras 4, 8 e 14) dos 12 poços amostrados (Tabela 4). Para os demais metais, os coeficientes de perigo permaneceram abaixo da unidade, apontando para a ausência de perigo associado à exposição ambiental por ingestão de águas. A análise dos índices de perigo demonstrou que quatro poços representavam risco quanto ao consumo humano (Tabela 4), sob uma perspectiva de adição de efeitos sobre o organismo. Nesse sentido, o Ni aparece como metal que mais incrementa o perigo total (entre $\sim 50$ a $90 \%$ ) (Tabela 4), indicando, em abordagem de rastreamento, que deve ser considerado como um contaminante prioritário para estudos mais aprofundados. Mais uma vez, sugere-se que a ocorrência anômala do $\mathrm{Ni}$ na geologia regional possa ter desempenhado papel importante na ocorrência de anomalias hidrogeoquímicas e/ou que a contaminação seja oriunda do solo em construções inadequadas do poço. É importante também ressaltar que o Hg também contribui com uma parcela importante do acréscimo de perigo (entre 10 e $25 \%$ ). caso, a pecuária realizada na ausência de condições básicas de higiene pode piorar o cenário.

A presença de E. colié indicadora da ocorrência potencial de outros importantes patógenos associados à falta de saneamento básico e de veiculação hídrica, causadores da hepatite, salmoneloses, entre outras doenças. Macler e Nerkle (2000) e Entry e Farmer (2001) alertam ainda para a mobilidade e proliferação desses patógenos em aquíferos, o que depende diretamente das condições físico-químicas do meio, sem contar com a recorrente contaminação que se sobrepõe ao decaimento natural. Dessa forma, os resultados obtidos são de fato preocupantes e requerem a adoção de medidas corretivas visando a melhoria das condições de saneamento e higiene.

A estimativa numérica de riscos não cancerígenos, em abordagem de rastreamento para exposição ambiental de crianças via ingestão de águas (Tabela 5), revelou que 4 (amostras 2, 4, 8 e 14) dos 12 poços estudados apresentaram coeficientes de perigo acima da unidade, sendo o valor máximo de 5,3 unidades, para o Ni, em um poço (poço 4) (Tabela 5). Ainda, os índices de perigo revelaram que 8 dos 12 poços estudados apresentavam risco à saúde humana, sendo esses valores até 10 vezes maiores do que aqueles obtidos para os adultos. Também nesse caso, o Hg contribui com uma parcela importante do acréscimo de perigo (entre $\sim 10$ e $75 \%$ ), chegando a ser majoritário em alguns poços.

Este é o primeiro trabalho realizado com uma abordagem integrada e abrangente, em águas subterrâneas do município de Capitão Gervásio de Oliveira. Entretanto, é preciso ressaltar que a metodologia de avaliação de risco, em abordagem de rastreamento, considera cenários bastante conservativos de exposição e de riscos à saúde humana. É recomendado realizar o monitoramento da qualidade das águas subterrâneas ao longo de um maior período de tempo, visando decrescer as incertezas quanto às variações sazonais dos teores de metais e neste caso, principalmente, de $\mathrm{Ni}$ e de $\mathrm{Hg}$, nas águas subterrâneas consumidas pela população. 


\begin{tabular}{ccc}
\hline Pontos de coleta & Coliformes totais (NMP) & Escherichia coli (NMP) \\
\hline 1 & 53 & 3,1 \\
\hline 2 & $>2.419,6$ & 1 \\
\hline 3 & 547,5 & 26,2 \\
\hline 4 & $>2.419,6$ & 980,4 \\
\hline 5 & 5,2 & $<1,0$ \\
\hline 8 & 2 & $<1,0$ \\
\hline 11 & 64,4 & $<1,0$ \\
\hline 12 & 5,2 & 2 \\
\hline 13 & 30,1 & 30,1 \\
\hline 19 & $1.553,1$ & 35 \\
\hline
\end{tabular}

Tabela 3

Determinação de coliformes totais e de Escherichia coli em águas subterrâneas coletadas em Capitão Gervásio de Oliveira, Piauí.

\begin{tabular}{|c|c|c|c|c|c|c|c|c|c|c|c|}
\hline \multirow{2}{*}{ Amostras } & \multicolumn{5}{|c|}{ Coeficiente de perigo } & \multirow{2}{*}{ Índice de perigo } & \multicolumn{5}{|c|}{ Contribuição para o índice de perigo (\%) } \\
\hline & $\mathrm{Ba}$ & B & $\mathrm{Hg}$ & $\mathrm{Ni}$ & Zn & & $\mathbf{B a}$ & B & $\mathrm{Hg}$ & $\mathrm{Ni}$ & Zn \\
\hline 1 & $\mathrm{DI}$ & 0,01 & 0,3 & 0,1 & 0,0009 & 0,4 & & & & & \\
\hline 2 & 0,03 & 0,03 & 0,2 & 0,7 & 0,003 & $1,0^{*}$ & 4 & 3 & 23 & 70 & - \\
\hline 3 & 0,03 & 0,03 & 0,3 & 0,03 & 0,001 & 0,3 & & & & & \\
\hline 4 & 0,03 & 0,02 & 0,2 & $1,5^{*}$ & 0,004 & $1,7^{*}$ & 2 & 1 & 11 & 86 & - \\
\hline 5 & 0,01 & 0,02 & 0,08 & 0,08 & 0,0009 & 0,2 & & & & & \\
\hline 11 & 0,1 & 0,02 & 0,2 & 0,04 & 0,2 & 0,6 & & & & & \\
\hline 13 & 0,03 & 0,02 & 0,05 & 0,01 & 0,08 & 0,1 & & & & & \\
\hline 14 & 0,1 & 0,03 & 0,3 & $1,3^{*}$ & 0,002 & $1,7^{*}$ & 7 & 2 & 17 & 74 & - \\
\hline 18 & DI & 0,03 & 0,07 & 0,02 & 0,03 & 0,1 & & & & & \\
\hline 19 & 0,01 & 0,02 & 0,07 & 0,01 & 0,003 & 0,1 & & & & & \\
\hline
\end{tabular}

* Coeficiente ou índice de perigo que excede a unidade.

DI: dado indisponível.

Tabela 4

Valores de coeficientes e índices de perigo: exposição de adultos via ingestão de água contaminada por metais em Capitão Gervásio de Oliveira, Piauí.

\begin{tabular}{|c|c|c|c|c|c|c|c|c|c|c|c|}
\hline \multirow{2}{*}{ Amostras } & \multirow{2}{*}{$\mathrm{Ba}$} & \multirow{2}{*}{ B } & \multirow{2}{*}{$\mathrm{Hg}$} & \multirow{2}{*}{$\mathrm{Ni}$} & \multirow{2}{*}{ Zn } & \multirow{2}{*}{ Índice de perigo } & \multicolumn{5}{|c|}{ Contribuição para o índice de perigo (\%) } \\
\hline & & & & & & & $\mathbf{B a}$ & B & $\mathrm{Hg}$ & $\mathrm{Ni}$ & Zn \\
\hline 1 & $\mathrm{DI}$ & 0,05 & 1,0 & 0,5 & 0,003 & $1,5^{*}$ & 0 & 3 & 64 & 32 & 0 \\
\hline 2 & 0,1 & 0,09 & 0,8 & $2,3 *$ & 0,01 & $3,3 *$ & 4 & 3 & 23 & 70 & 0 \\
\hline 3 & 0,1 & 0,09 & 0,9 & 0,08 & 0,004 & $1,2 *$ & 8 & 8 & 76 & 7 & 0 \\
\hline 4 & 0,1 & 0,08 & 0,7 & $5,3 *$ & 0,01 & $6,2 *$ & 2 & 1 & 11 & 86 & 0 \\
\hline 5 & 0,05 & 0,07 & 0,3 & 0,3 & 0,003 & 0,7 & & & & & \\
\hline 11 & 0,5 & 0,06 & 0,8 & 0,1 & 0,5 & $2,0^{*}$ & 23 & 3 & 40 & 7 & 27 \\
\hline 13 & 0,1 & 0,08 & 0,2 & 0,03 & 0,03 & 0,4 & & & & & \\
\hline 14 & 0,4 & 0,1 & 1,0 & $4,4^{*}$ & 0,008 & $6,0^{*}$ & 7 & 2 & 17 & 74 & 0 \\
\hline 18 & $\mathrm{DI}$ & 0,1 & 0,2 & 0,06 & 0,1 & 0,5 & & & & & \\
\hline 19 & 0,03 & 0,08 & 0,2 & 0,03 & 0,01 & 0,4 & & & & & \\
\hline
\end{tabular}

* Coeficiente ou índice de perigo que excede ou se aproxima da unidade.

DI: dado indisponível.

\section{Tabela 5}

Valores de coeficientes e índices de perigo: exposição de crianças via ingestão de água contaminada por metais em Capitão Gervásio de Oliveira, Piauí. 


\section{CONCLUSÕES}

As amostras de água subterrânea utilizadas no estudo apresentaram concentrações de metais acima daqueles recomendados na legislação vigente, sobretudo no que diz respeito ao $\mathrm{Zn}$, Ni e Hg. Concentrações de $\mathrm{Cl}^{-}$acima do permitido para a proteção da saúde humana também foram detectadas. No caso do $\mathrm{Ni}$, possivelmente as anomalias supracitadas estão associadas a atividades de mineração do metal. Ainda, a avaliação microbiológica indicou que a água da maioria dos poços amostrados estava imprópria para consumo humano.

A aplicação da metodologia de avaliação de risco indicou que o $\mathrm{Ni}$ e o $\mathrm{Hg}$ parecem ser os metais de maior importância no acréscimo de risco à saúde humana. Para o Ni, as anomalias de concentração podem estar correlacionadas à mineração, devendo ser priorizado em futuras medidas de tratamento da água. Os depósitos de Ni são de gênese primária, com jazidas estimadas em 25 milhões de toneladas, sendo atualmente exploradas pela Companhia Vale do Rio Doce. A metodologia supracitada demonstrou ser eficiente na avaliação de águas subterrâneas simultaneamente contaminadas por distintos metais, com a indicação de contaminantes não prioritários e de contaminantes-chave (nesse caso, $\mathrm{Ni}$ e $\mathrm{Hg}$ ), bem como de poços críticos de contaminação. De fato, o zoneamento dessas áreas críticas é essencial a qualquer tipo de planejamento ou tomada de decisão em medidas de saúde pública e de controle ambiental e, nesse sentido, a metodologia de avaliação de risco possui elevado potencial de aplicação como ferramenta de gestão dos recursos hídricos subterrâneos do Estado do Piauí.

\section{AGRADECIMENTOS}

Os autores agradecem ao geólogo Ronildo Castelo Branco e ao Sr. Expedito Rodrigues de Oliveira, pelo ines- timável apoio nos trabalhos de campo. e ao Dr. Adão B. da Luz, pelo incentivo para a realização deste projeto.

\section{REFERÊNCIAS}

ATSDR - Agency for Toxic Substances and Disease Registry 2007a. Toxicological profile for mercury. Disponível em: http://www.atsdr.cdc.gov/toxprofiles/tp46. pdf. Acessado em mar 2013.

ATSDR - Agency for Toxic Substances and Disease Registry 2007b. Toxicological profile for zinc. Disponível em: http://www.atsdr.cdc.gov/toxprofiles/tp60.pdf. Acesso em 24 mar 2013.

ATSDR - Agency for Toxic Substances and Disease Registry 2007c. Toxicological profile for barium and barium compounds. Disponível em: http://www.atsdr. cdc.gov/toxprofiles/tp24.pdf. Acessado em mar 2011.

Barreto F.C. \& Araujo S.M.H.A. 2011. Intoxicação Alumínica na DRC. Jornal Brasileiro de Nefrologia, 30(Suppl 1):21-25.

Berber M.G., Araújo L.M., Oliveira C.F., Troster E.J., Vaz F.A. 2007. Choque refratário e óbito após intoxicação por sulfato ferroso. Revista Paulista de Pediatria, 25(4):385-388.

Brasil. Ministério da Saúde. 2011. Portaria n ${ }^{\circ}$ 2.914. Dispõe sobre os procedimentos de controle e de vigilância da qualidade da água para consumo humano e seu padrão de potabilidade. Disponível em: http://bvsms.saude.gov.br/bvs/ saudelegis/gm/2011/prt2914_12_12_2011.html. Acessado junho 2014.

Castilhos Z.C., Castro A.L., Ramos A.S., Lima C.A., Rodrigues A.P.C. 2005. Avaliação de risco à saúde humana: conceitos e metodologia. CETEM/ Rio de Janeiro, v. 1, p. 53.

Cesar R., Colonese J., Silva M., Egler S., Bidone E., Castilhos Z., Polivanov H. 2011. Distribuição de mercúrio, cobre, chumbo, zinco e níquel em sedimentos de corrente da bacia do Rio Piabanha, Estado do Rio de Janeiro. Geochimica Brasiliensis, 25(1):35-45.

CETESB - Companhia de Tecnologia de Saneamento Ambiental. 2005. Valores Orientadores para Solos e Águas Subterrâneas no Estado de São Paulo. Disponível em: http://www.cetesb.sp.gov.br/Solo/relatorios/tabela_ valores_2005.pdf. Acessado em mar 2011.

CONAMA - Conselho Nacional do Meio Ambiente. 2008. Resolução no 396. Dispõe sobre a classificação e diretrizes ambientais para o enquadramento das águas subterrâneas e dá outras providências. Diário Oficial da União 
$n^{\circ}$ 66, de 07 de abril de 2008. Seção 1. P. 64-68. Disponível em: http://www. mma.gov.br/port/conama/legiabre.cfm?codlegi=562. Acessado em out 2013.

CPRM - Serviço Geológico do Brasil. 2004. Projeto Cadastro de Fontes de Abastecimento por Água Subterrânea. Diagnóstico do Município de Capitão Gervásio de Oliveira. Disponível em: http://www.cprm.gov.br/rehi/atlas/piaui/ relatorios/050.pdf. Acessado em mar 2013.

Entry J.A. \& Farmer N. 2001. Movement of coliform bacteria and nutrients in ground water flowing through basalt and sand aquifers. Journal of Environmental Quality, 30(5):1533-1539.

IBGE - Instituto Brasileiro de Geografia e Estatística. 2010. Sistema IBGE de Recuperação Automática - SIDRA. Disponível em: http://www.sidra.ibge.gov. br. Acessado em out 2013.

IDEXX Laboratories Inc. 2002. Cartilha explicativa do método colilert, tecnologia do Substrato. Definido. Disponível em: http://www.idexx.com/resource-library/ water/colilert-procedure-en.pdf. Acesso em set 2013.

Macler B.A. \& Merkle J.C. 2000. Current knowledge on groundwater microbial pathogens and their control. Hydrogeology Journal, 8:29-40

USEPA - United States Environmental Protection Agency. 1989. Risk Assessment Guidance for Superfund. vol I: Human Health Evaluation Manual. Washington, DC.

USEPA - United States Environmental Protection Agency. 2014. Integrated Risk Information System. Disponível em: http://www.epa.gov.br/iris. Acessado em junho 2014 